\title{
ESTUDO COMPARATIVO DE FERRAMENTAS MODERNAS DE ANÁLISE APLICADAS À QUALIDADE DA ENERGIA ELÉTRICA
}

\author{
Mário Oleskovicz ${ }^{*}$ \\ Denis V. Coury* \\ Adriano A. F. M. Carneiro* \\ Elcio F. Arruda* \\ Odilon Delmont F.* \\ Silvio A. Souza*
*Laboratório de Sistemas de Energia Elétrica, Escola de Engenharia de São Carlos, Universidade de São Paulo Avenida Trabalhador São-carlense, 400
13566-590, São Carlos, São Paulo, Brasil

\begin{abstract}
This work presents a comparative study amongst tools for the analysis of Power Quality, emphasizing the Windowed Fourier Transform (WFT), the Wavelet Transform (WT) as well as Artificial Neural Networks (ANN). From the tools mentioned, the WFT and WT are applicable to the detection, location and classification of abnormalities related to voltage waveforms in a distribution system for the diagnosis of the present situation. As it will be shown, the classification of the phenomena can also be performed using alternative methods, as the ANN. Tests show that the mentioned tools have great potentiality to be applied to the evaluation of Power Quality. Some peculiarities of each tool will be emphasized.
\end{abstract}

KEYWORDS: Power Quality, Wavelet Transform, Windowed Fourier Transform and Artificial Neural Networks.

\section{RESUMO}

Este trabalho apresenta um estudo comparativo entre ferra-

\footnotetext{
Artigo submetido em 30/08/2005

1a. Revisão em 24/11/05

2a. Revisão em 31/08/06

Aceito sob recomendação do Editor Associado

Prof. Carlos Alberto de Castro Junior
}

mentas de análise, aplicável à Qualidade da Energia Elétrica (QEE), enfatizando-se a Transformada de Fourier com Janela (TFJ), a Transformada Wavelet (TW) e Redes Neurais Artificiais (RNAs). Das ferramentas apontadas, a TFJ e a TW, mostram-se aplicáveis à detecção, localização e classificação de distúrbios agregados às formas de ondas de tensão em um sistema de distribuição, com o intuito de prover um diagnóstico preciso das situações enfrentadas. Como será evidenciado, além da detecção, localização e classificação pelas técnicas citadas, os distúrbios também podem ser classificados segundo sua natureza, utilizando-se métodos alternativos, como pela aplicação de RNAs. Os testes efetuados mostraram que as ferramentas mencionadas possuem uma grande potencialidade quanto às suas aplicações na avaliação da QEE. Neste contexto, serão apontadas algumas peculiaridades e características inerentes a cada ferramenta.

PALAVRAS-CHAVE: Qualidade da Energia Elétrica, Transformada de Fourier com Janela, Transformada Wavelet e Redes Neurais Artificiais.

\section{INTRODUÇÃO}

A Qualidade da Energia Elétrica (QEE) constitui na atualidade um fator crucial para a competitividade de praticamente 
todos os setores industriais e de serviços. Assim, para manter o nível de tensão dentro de certos limites operacionais aceitáveis, tanto em nível de transmissão como de distribuição, são necessárias medidas de controle e de acompanhamento tanto dos órgãos de fiscalização como das concessionárias fornecedoras de energia.

Para avaliar o quanto um sistema está operando fora de suas condições normais, duas grandezas elétricas básicas podem ser empregadas. Estas são a tensão e a freqüência. A freqüência em um sistema interligado situa-se na faixa de $60 \pm$ $0,5 \mathrm{~Hz}$. Por outro lado, em relação à tensão, três aspectos principais devem ser observados: a forma de onda, a qual deve ser o mais próximo possível de uma senóide; a simetria de fases do sistema elétrico e as magnitudes das tensões dentro de limites aceitáveis.

Entretanto, existem alguns fenômenos, aleatórios ou intrínsecos, que ocorrem no sistema elétrico fazendo com que os aspectos acima citados sofram alterações, deteriorando a qualidade do fornecimento de energia elétrica. Dentre os fenômenos podemos citar: afundamentos e/ou elevações de tensões, as interrupções, distorções harmônicas, flutuações de tensão, transitórios oscilatórios ou impulsivos, ruídos, sobretensões e subtensões (Dugan et al, 1996). As situações transitórias em sistemas de potência, as quais freqüentemente apresentam um considerável efeito sobre a operação normal de um sistema, são comuns e, na prática, podem ser ocasionadas por descargas atmosféricas, correntes de magnetização dos transformadores, faltas sustentadas, correntes de partida de grandes motores, ou ainda pelos efeitos capacitivos e de chaveamento em linhas de transmissão. A análise e o entendimento destes transitórios associados às condições anormais têm sempre auxiliado na mitigação e retificação dos mesmos.

Diversas ferramentas como a Transformada de Fourier com Janela (TFJ), Transformada Wavelet (TW) e Redes Neurais Artificiais (RNAs) tem sido usadas para análise de distúrbios em Sistemas Elétricos de Potência (SEP) ligados à QEE conforme relatam Aggarwal e Kim (2000) e Huang et al., (1998).

Este trabalho apresenta uma análise comparativa do emprego independente da TFJ e da TW para detectar, localizar e classificar o distúrbio agregado às formas de ondas de tensão referenciadas a um sistema real de distribuição. Além destas duas distintas abordagens, os distúrbios são classificados de forma alternativa e paralela, segundo sua natureza, pela aplicação de Redes Neurais Artificiais (RNAs).

As grandezas analisadas referem-se a valores amostrados de tensões de um sistema elétrico real, cujos dados foram fornecidos pela CPFL - Companhia Paulista de Força e Luz e simulados pela aplicação do software ATP - Alternative Transients Program (1987). Os softwares Matlab ${ }^{\circledR}$ e o NeuralWorks Professional II/Plus (1998), também são utilizados para as respectivas aplicações da TFJ e TW, bem como para as RNAs propostas.

Como aplicação prática, visando os interesses do setor energético atual, um software completo para a análise da QE fornecida por um dado sistema elétrico foi implementando e extensamente testado, com resultados bastante promissores.

\section{CONCEITOS BÁSICOS DAS FERRA- MENTAS APLICADAS À QEE}

\subsection{A Transformada de Fourier com Ja- nela}

Para se obter informações aceitáveis no estudo de fenômenos ligados à QEE, a obtenção de informações em ambos os domínios, tempo e freqüência, são fundamentais na caracterização de tais fenômenos. Tais informações podem ser conseguidas por meio da Transformada de Fourier com Janela (TFJ) conforme apresentado por Hensley et al. em 1999. A mesma é referenciada como uma versão com janela da Transformada de Fourier discreta no tempo. A largura da janela pode ser ajustada e deslocada para explorar uma grande quantidade de dados referentes à QEE. Quando há a necessidade de focar uma região problemática específica, a largura da janela é diminuída para uma análise mais detalhada, enquanto que a largura da janela pode ser aumentada quando não forem detectados problemas referentes à QEE.

Gu \& Bollen (2000), propuseram uma análise onde a STFT (Short Time Fourier Transform) é usada para a análise no domínio do tempo e da freqüência, enquanto filtros wavelets dyadic são usados para a análise no domínio do tempo e escala. A STFT discreta pode ser vista como uma representação passa-baixa das saídas de um filtro passa-banda, onde todos os filtros passa-banda têm a mesma largura de banda determinada pela janela selecionada. Com a escolha adequada do tamanho da janela, a STFT discreta é também capaz de detectar e analisar transitórios em um distúrbio de tensão.

Cabe comentar que a TFJ, também conhecida como Transformada de Fourier de Curto Tempo, a mesma usada por Gu \& Bollen (STFT) pode ser usada para análise no domínio do tempo e da freqüência de sinais não estacionários, visto que a Transformada de Fourier convencional torna-se inadequada. A TFJ discreta decompõe um sinal variante no tempo em componentes no domínio do tempo e da freqüência. Portanto, permite caracterizar de forma mais eficiente a evolução no tempo de cada componente do sinal (Gu \& Bollen, 2000).

Dado um sinal $x(m)$, a TFJ discreta é definida como: 


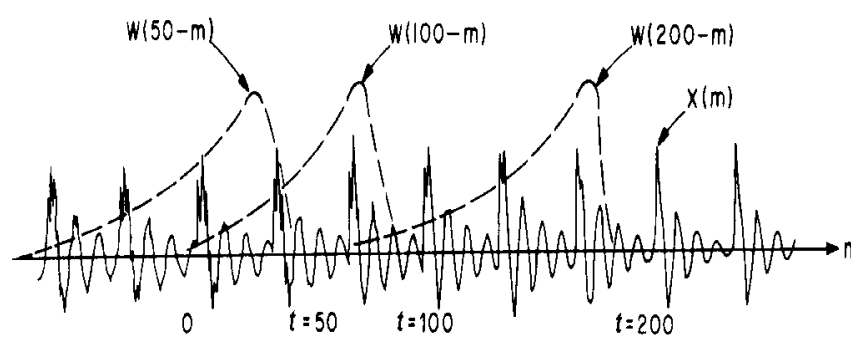

Figura 1: Esboço de $\mathrm{x}(\mathrm{m})$ e $\mathrm{w}(\mathrm{t}-\mathrm{m})$ para vários valores de $\mathrm{t}$.

$$
X_{t}\left(e^{j \omega}\right)=\sum_{m=-\infty}^{\infty} w(t-m) x(m) e^{-j \omega m}
$$

\section{Onde:}

$\omega=2 \pi k / N$ é a freqüência em radianos;

$N$ é o número de bandas de freqüências;

$w(m)$ é a janela simétrica selecionada de tamanho $L$, sendo $L \leq N$ se a reconstrução do sinal é requerida.

Na equação (1), $w(t-m)$ é uma seqüência de janelas as quais determinam a porção de entrada do sinal em análise para um índice de tempo particular, $t$. A TFJ é claramente uma função de duas variáveis: do índice tempo $(t)$, o qual é discreto, e da variável frequiência $(\omega)$, a qual é contínua.

Quando consideramos $X_{t}\left(e^{j \omega}\right)$ como a transformada de Fourier de uma seqüência $w(t-m) x(m),-\infty<m<\infty$, para $t$ fixo, temos que a TFJ será função do índice tempo, $t$, o qual toma todos os valores inteiros de modo a "deslizar" a janela, $w(t-m)$, ao longo da seqüência, $x(m)$. Este processo é descrito na Figura 1, onde o sinal e a janela são representados, por conveniência, como funções contínuas, mesmo sendo eles definidos para valores inteiros de $m$ e $t--m$.

A seguir serão comentadas as definições dos três tipos de janelas utilizadas e comparadas nesse trabalho.

\subsubsection{Janela Retangular}

A janela retangular é unitária sobre o intervalo em observação, e pode ser considerada como um conjunto de seqüências finito aplicado ao sinal em análise. Tal janela é definida e ilustrada pela Equação e Figura (2) respectivamente, caracterizando a resposta em freqüência.

$$
w(n)= \begin{cases}1, & n=0,1, \ldots, M-1 \\ 0, & \text { caso contrário }\end{cases}
$$

Na equação, $M$ representa o tamanho da janela em amos-
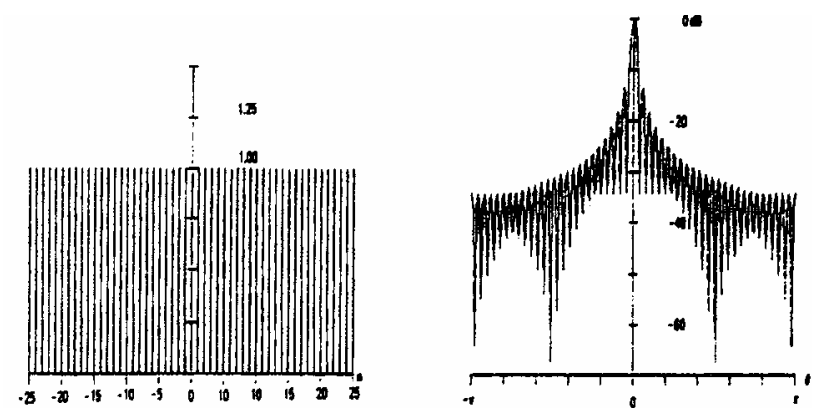

Figura 2: Janela Retangular e resposta em freqüência - magnitude $(\mathrm{dB})$

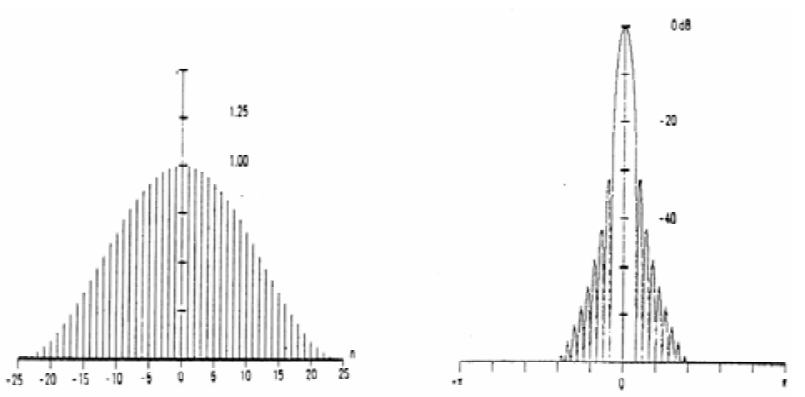

Figura 3: Janela de Hanning e resposta em freqüência - magnitude $(\mathrm{dB})$

tras $(M=0, \ldots, 127)$, quando considerada uma janela com dados amostrados na freqüência de $7.680 \mathrm{~Hz}$ (freqüência de operação do sistema: $60 \mathrm{~Hz}$ ).

\subsubsection{Janela de Hanning}

A janela de Hanning pode ser escrita como segue:

$w(n)=\left\{\begin{array}{l}0.5-0.5 * \cos \left(\frac{2 \pi n}{(M-1)}\right), \quad 0 \leq n \leq M-1 \\ 0, \quad \text { caso contrário }\end{array}\right.$

A Figura 3, mostra a janela Hanning e sua respectiva resposta em frequiência.

\subsubsection{Janela de Kaiser}

A janela de Kaiser é definida da seguinte maneira:

$$
w(n)=\left\{\begin{array}{l}
\frac{I_{0}\left[\beta\left(1-[(n-\alpha) / \alpha]^{2}\right)^{1 / 2}\right]}{I_{0}(\beta)}, \quad 0 \leq n \leq M \\
0, \quad \text { caso contrário }
\end{array}\right.
$$



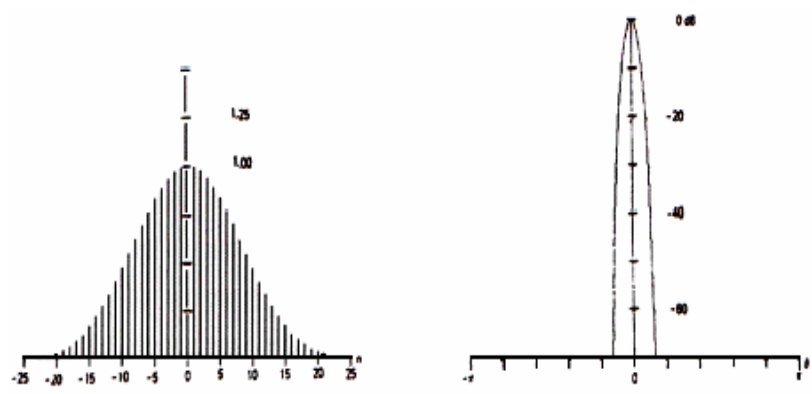

Figura 4: Janela de Kaiser e resposta em frequiência com $\beta=$ 3.0 - magnitude $(\mathrm{dB})$

Onde $\alpha=M / 2$, e $\mathrm{I}_{0}($.$) representam a função Bessel de or-$ dem zero modificada de primeiro tipo. A Figura 4 mostra a janela de Kaiser e sua respectiva resposta em freqüência.

Observa-se nas Figuras 2, 3 e 4, que quanto mais estreito o lóbulo principal, menor a atenuação do lóbulo secundário. Idealmente, uma janela deve ser um impulso no domínio da freqüência, o que implica numa duração infinita.

\subsection{A Transformada Wavelet}

A análise de dados de acordo com escalas variáveis no domínio do tempo e da freqüência é a idéia básica da utilização da Transformada Wavelet. O termo Wavelet foi originariamente introduzido por J. Morlet, sendo a base matemática de suas idéias formalizada pelo físico teórico Alex Grossmann, (Santoso et al., 1996).

Do crescente número de trabalhos relacionados à TW, destacamos inicialmente Santoso et al. (1996), cuja idéia básica do trabalho está na decomposição de um dado sinal distorcido em outros sinais que representam uma versão atenuada do sinal original. Já com Angrisani et al. (1998) os mesmos combinam o uso da Transformada Wavelet Contínua (TWC) com a reconstrução do sinal por meio da Transformada $W a-$ velet de Tempo Discreto (TWTD). Huang et al. (1998) mostram que características de distúrbios não estacionários foram melhores monitorados através das Wavelets. Em Gaouda et al. (1999) encontramos uma técnica que relaciona a energia do sinal distorcido com a energia de cada componente da expansão em multiresolução e seus coeficientes Wavelet. A TWC é apresentada, como um método mais seguro para a detecção e medição de afundamentos de tensão, flickers e transitórios, por Poisson et al. (1999). Zheng et al. (1999) fazem a modelagem de componentes do sistema tais como resistor, indutor e capacitor no domínio da TWTD. Já Poisson et al. (2000) apresentam um método que possibilita uma classificação precisa de eventos transitórios e as características destes eventos são facilmente extraídas de seu plano tempo-freqüência. Santoso et al. (2000) apresentam um trabalho que traz a união da Transformada de Fourier (TF) com a TW.

A TW é uma ferramenta matemática para análise de sinais, similar à TF. No entanto, a TW decompõe o sinal em diferentes escalas, com diferentes níveis de resolução, a partir de uma única função. Diferentemente da TF que fornece uma representação global do sinal, a TW apresenta representações locais no domínio do tempo e da frequiência de um dado sinal. A Transformada Wavelet Discreta (TWD) de uma dada função $f$ é representada pela Equação (5):

$$
(T W D \cdot)(a, b)=\sum f(t) \overline{\psi_{a, b}(t)} d t
$$

Nesta equação, os parâmetros $a$ e $b$, variam discretamente em $\Re$, sendo as funções $\psi_{a, b}$ denominadas Wavelet mães e definidas de acordo com a Equação (6):

$$
\psi_{a, b}(t)=\frac{1}{\sqrt{a}} \psi\left(\frac{t-b}{a}\right) .
$$

Analisando a Equação (5) pode-se perceber que a TWD depende de dois parâmetros, $a$ e $b$, que correspondem, respectivamente, às informações da escala, ou dilatação, e translação, ou tempo. Tal equação decompõe $f$ em uma superposição de Wavelet mães $\psi_{a, b}$, sendo os coeficientes desta superposição obtidos pela TWD de $f$.

\subsubsection{Análise Multiresolução}

A técnica de Análise Multiresolução (AMR) permite a decomposição de um dado sinal em diferentes níveis de resolução, fornecendo importantes informações no domínio do tempo e da frequiência. Por esta técnica, o sinal analisado é primeiramente decomposto em dois outros sinais, uma versão detalhada e outra atenuada, através de filtros passa alta $(h 1)$ e passa baixa $(h 0)$, que são representados matematicamente por funções Wavelets e funções escala, respectivamente. Este fato é evidenciado na Figura 5, a qual representa o processo de filtragem que é acompanhado também de um operador downsampling, que reduz a quantidade de informações a ser processada. Observa-se, na figura, que o sinal atenuado proveniente do filtro passa baixa é novamente decomposto, resultando em dois novos sinais detalhados e atenuados, em níveis de freqüência diferentes. Estes fornecem informações diretas, relativas ao sinal original, no domínio da freqüência e do tempo, (Angrissani et al., 1998).

Neste trabalho, a wavelet mãe Daubechies de ordem 4 (db4) foi empregada, conforme mostrado em Arruda et al. (2002) e também em muitos artigos desta área. Esta wavelet mãe é adequada para a decomposição dos distúrbios analisados. 


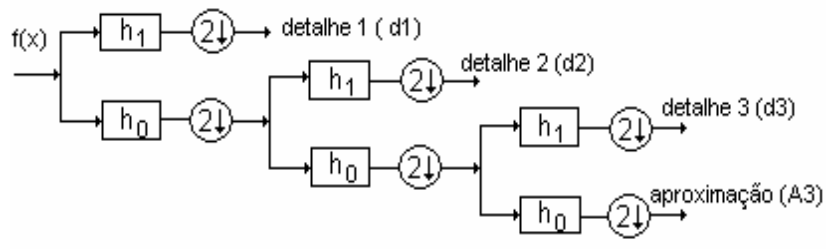

Figura 5: Processo de decomposição de um sinal - AMR.

\subsection{Redes Neurais Artificiais}

Dentre as possíveis aplicações de Redes Neurais Artificiais (RNAs), destacamos o seu emprego como reconhecimento de padrões, que em termos gerais, é a ciência que compreende a identificação e classificação da informação em categorias. Desta maneira, esta técnica apresenta interessantes características para classificação de distúrbios relacionados à $\mathrm{QEE}$, tais quais as metodologias descritas anteriormente. Evidências de tais aplicações começam a despontar como em Oleskovicz et al. (2003) e em Gaing (2004).

\section{UMA VISÃO GERAL DO TRABALHO}

Considerando-se a aplicação da TFJ e da TW, afirma-se que é possível constantemente monitorar o sistema, através dos seus valores amostrados de tensões, a uma frequiência de 7,68 $\mathrm{kHz}$. Justifica-se tal valor, devido à freqüência de amostragem usualmente empregada pelos instrumentos de medição e obtenção de dados, como por exemplo, o BMI (Basic Measuring Instrument), que apresenta um valor em torno de 7,7 $\mathrm{kHz}$.

Com uma janela de dados móvel, as ferramentas poderão, de forma independente e com precisão, detectar uma descontinuidade nos sinais com base nos ciclos referenciados. Deste procedimento, torna-se viável a comparação entre as amplitudes das amostras caracterizadas em cada janela sob análise, seja pela TFJ ou pela TW, sendo possível então, a detecção do momento inicial do distúrbio e, conseqüentemente, sua localização no tempo (Souza, 2004 e Oleskovicz et al., 2003).

Como apontado, a idéia é monitorar constantemente as três fases de tensões de determinado sistema de forma independente pela TFJ e pela TW e, tão logo sejam caracterizadas descontinuidades nos sinais, permitir digitalmente, o armazenamento de até 10 ciclos pós-fenômeno, para uma completa análise dos sinais. Entende-se por completa análise, a determinação exata dos instantes de inserção e extinção dos fenômenos sobre o sistema, caracterização dos componentes de frequiência e magnitudes presentes nos sinais e a resposta do sistema frente ao distúrbio com a conseqüente classificação dos mesmos. Esta completa análise é totalmente baseada

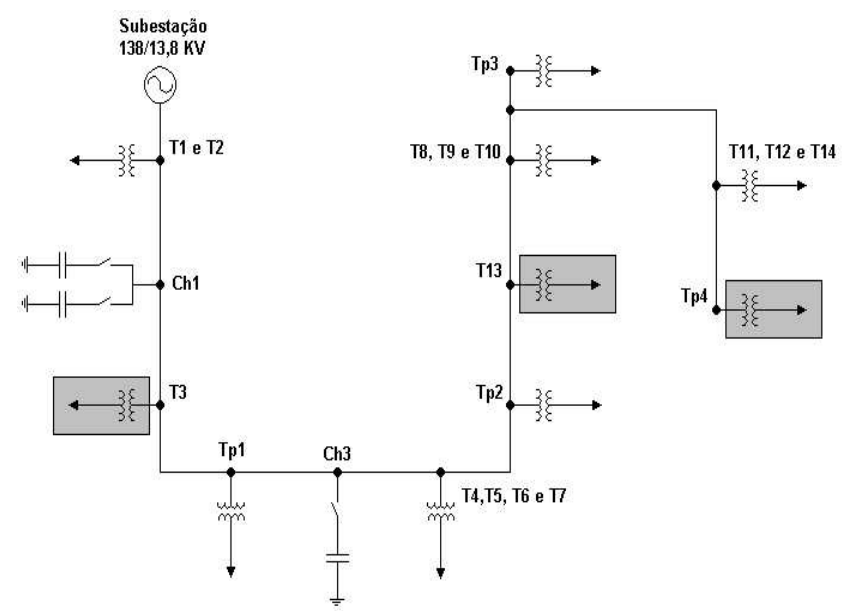

Figura 6: Diagrama do sistema elétrico de distribuição analisado.

na TFJ ou na TW, tomando-se como parâmetros de observância a análise quantitativa de limiares associados à representação do sistema. De forma independente e alternativa, quando da informação de ocorrência de algum distúrbio, seja pela TFJ ou pela TW, um módulo inteligente, caracterizado por RNAs, pode ser ativado para classificar em tempo hábil o fenômeno ocorrido. O emprego de RNAs antecipa e valida os resultados a serem apresentados pela aplicação da TFJ e da TW no que diz respeito à classificação dos fenômenos.

Os comentários que seguem buscam delinear o sistema elétrico analisado, com a aplicadção das ferramentas, e as principais considerações e observações pertinentes a cada aplicação, visando ressaltar as vantagens e/ou desvantagens das abordagens sugeridas.

\section{SISTEMA ELÉTRICO ANALISADO}

Como grandezas para a análise da QEE, temos valores amostrados de tensões de um sistema elétrico real, cujos dados foram fornecidos pela CPFL - Companhia Paulista de Força e Luz e simulados pela aplicação do software ATP (Figura 6). Deve ser ressaltado que a modelagem deste sistema de distribuição primário, na medida do possível, apresenta grande semelhança com os encontrados na prática. Inúmeras considerações práticas foram adotadas até a obtenção e teste do mesmo, em um trabalho conjunto entre as partes interessadas.

$\mathrm{Na}$ figura, o transformador da subestação (Subestação138/13,8 kV, 25 MVA), os transformadores de distribuição 3 e 13 (T3 e 13, 45 kVA) e o transformador particular 4 (Tp 4, $45 \mathrm{kVA}$ ), que aparecem destacados, foram modelados considerando-se suas curvas de saturação. O modelo 
das cargas do lado secundário destes trafos segue características específicas que denotam situações reais de carga. Já os transformadores particulares 1, 2 e 3 (Tp1, 2 e 3 ) foram modelados sem considerar as respectivas curvas de saturação. Logo, as cargas foram referidas ao primário com uma parcela RL em paralelo com um capacitor para a devida correção do fator de potência, originalmente de 0,75 e posteriormente corrigido para 0,92 . Os demais transformadores de distribuição foram modelados somente como cargas RL referidas ao primário, considerando-se um fator de potência geral de 0,95. Cabe ainda destacar que tanto os transformadores de distribuição quanto os particulares apresentam ligações delta-estrela, com resistência de aterramento de zero ohm. Além destes, três bancos de capacitores (um de 1200 kVAr e dois de 600 kVAr cada) estão instalados ao longo do sistema (BC 1, 2 e 3). O alimentador principal é constituído por cabo nu CA-477 MCM em estrutura aérea convencional, e seus trechos são representados por elementos RL acoplados.

Para validar as técnicas apresentadas (baseadas na TFJ e na TW), elaborou-se um conjunto de teste formado por 90 diferentes situações de operação sobre o sistema elétrico ilustrado, que foram apresentadas de forma automatizada e independente a cada algoritmo implementado. Destas situações simuladas, 34 referem-se a afundamentos e 26 a elevações de tensão, 8 a interrupções, 10 a ruídos e 12 a transitório oscilatório. Todos os fenômenos foram caracterizados tomando-se como ângulos de incidência $0^{\circ}$ e $90^{\circ}$.

\section{AS TÉCNICAS ADOTADAS}

\subsection{Abordagem baseada na TFJ}

A seguir, serão apresentados alguns resultados e considerações referentes à aplicação da TFJ (Souza, 2004).

Para a detecção do distúrbio empregando-se a TFJ, foi considerado o janelamento dos sinais sob análise e em regime normal de operação, utilizando-se um ciclo, com passos de deslocamento de meio ciclo. Com o janelamento de ambos os sinais, puderam-se efetuar comparações entre as amplitudes das amostras inseridas em cada janela, de maneira a acusar o início de qualquer distúrbio quando ultrapassado um determinado limiar. Assim, o algoritmo acusa o momento inicial de tal evento, realizando sua detecção e, conseqüentemente, a localização no tempo.

Os tempos de início dos diversos distúrbios analisados e obtidos pela lógica computacional implementada são apresentados na Tabela 1. Os resultados mostram que a técnica utilizada para detecção do momento inicial de tais fenômenos apresenta baixos erros percentuais em relação ao início real dos distúrbios simulados.
Tabela 1: Tempos de detecção inicial dos distúrbios.

\begin{tabular}{|c|c|c|c|c|}
\hline $\begin{array}{c}\text { Distúrbios } \\
\text { Analisados }\end{array}$ & $\begin{array}{c}\text { Angulo } \\
\text { de Inserção } \\
\left({ }^{\circ}\right)\end{array}$ & $\begin{array}{c}\text { Início Real } \\
\text { do Distúrbio } \\
(\mathrm{s})\end{array}$ & $\begin{array}{c}\text { Localização } \\
\text { do Distúrbio } \\
(\mathrm{s})\end{array}$ & $\begin{array}{c}\text { Erro } \\
\text { Encontrado } \\
(\%)\end{array}$ \\
\hline $\begin{array}{c}\text { Elevação de } \\
\text { Tensão }\end{array}$ & 0 & 0,0454 & 0,0456 & 0,02 \\
\hline $\begin{array}{c}\text { Afundamento } \\
\text { de Tensão }\end{array}$ & 90 & 0,0488 & 0,0489 & 0,01 \\
\hline $\begin{array}{c}\text { Interrupção } \\
\text { de Tensão }\end{array}$ & 0 & 0,0445 & 0,0447 & 0,02 \\
\hline $\begin{array}{c}\text { Transitório } \\
\text { Oscilatório }\end{array}$ & 0 & 0,0485 & 0,0489 & 0,04 \\
\hline Ruídos & 00 & 0,0445 & 0,0447 & 0,02 \\
\hline
\end{tabular}

Pela lógica computacional implementada, o algoritmo acusa o início e a localização no tempo de determinada anormalidade e então ativa a função seguinte que tratará da classificação do ocorrido.

A classificação é realizada por meio da TFJ com a utilização das Janelas Retangular, de Hanning e de Kaiser. O sinal analisado corresponde a janelas de 2 ciclos de duração com passos de deslocamento de um ciclo. Os mesmos foram avaliados por meio da função specgram, utilizando-se do software Matlab. Esta função fornece informações no domínio da freqüência e do tempo simultaneamente.

$\mathrm{Na}$ apresentação que segue, serão consideradas as componentes harmônicas até a $50^{a}$ ordem, normalizadas em relação à magnitude da freqüência fundamental do sistema, extraída do espectrograma.

$\mathrm{Na}$ classificação dos fenômenos relacionados às elevações, afundamentos e interrupções de tensão, as harmônicas da $2^{a}$ a $50^{a}$ ordem devem possuir amplitudes desprezíveis, como ilustrado na Figura 7.

\subsubsection{Estimação da Duração dos Distúrbios}

Após a detecção e conseqüente determinação do início do distúrbio sobre o sistema, as janelas posteriores, novamente caracterizadas por um ciclo do sinal em análise, tendo meio ciclo como passo de deslocamento, são utilizadas para estimar o tempo de permanência do fenômeno sobre o sistema. Pelas janelas subseqüentes, faz-se novamente uma análise em termos da amplitude caracterizada no sinal. Quando a diferença em amplitude entre duas janelas subseqüentes for maior que um determinado limiar, caracteriza-se uma distinta mudança nas condições no sistema, que para a análise em específico, foi condicionada como a volta à condição normal de operação. 


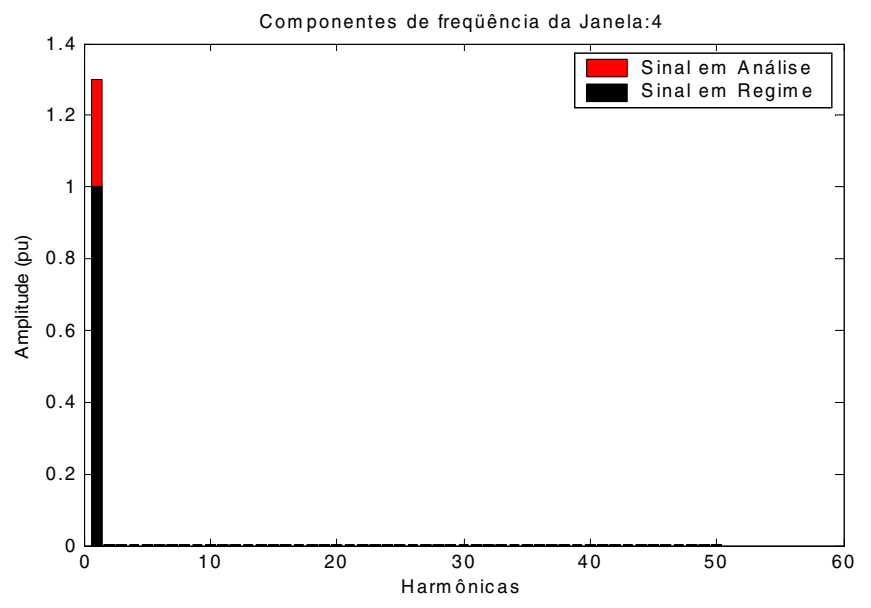

Figura 7: Análise espectral para uma elevação de tensão de $30 \%$.

Tabela 2: Erros médios obtidos através da comparação das janelas versus distúrbios.

\begin{tabular}{|c|c|c|c|}
\hline & \multicolumn{3}{|c|}{$\begin{array}{c}\text { Média dos Erros Referente aos } \\
\text { Distúrbios (\%) }\end{array}$} \\
\hline & $\begin{array}{c}\text { Elevaçâes } \\
\text { de Tensão }\end{array}$ & $\begin{array}{c}\text { Afundamentos } \\
\text { de Tensão }\end{array}$ & $\begin{array}{c}\text { Interrupções } \\
\text { de Tensão }\end{array}$ \\
\hline $\begin{array}{c}\text { Janela } \\
\text { Retangular }\end{array}$ & 1,2366 & 0,9701 & 0,2294 \\
\hline $\begin{array}{c}\text { Janela de } \\
\text { Hanning }\end{array}$ & 1,1585 & 1,0199 & 0,3175 \\
\hline $\begin{array}{c}\text { Janela de } \\
\text { Kaiser }\end{array}$ & 1,2353 & 0,9522 & 0,2300 \\
\hline
\end{tabular}

\subsubsection{A Classificação e Estimação dos Distúrbios}

Todos os casos de elevações, afundamentos e interrupções de tensão, foram corretamente classificados através da aplicação da TFJ considerando-se a amplitude estimada. A Tabela 2 reporta a média dos erros observados na estimação da amplitude dos fenômenos envolvidos, quando realizada empregando-se os três tipos de janelas mencionados.

Cabe ressaltar que todos os casos de transitórios oscilatórios e ruídos foram corretamente classificados, seguindo a metodologia explicitada nos comentários anteriores.

Pode ser observado na referida tabela que, considerando-se o erro global, os desempenhos dos diferentes tipos de janelas na análise são similares. No entanto, deve-se acrescentar que a janela retangular é preferível do ponto de vista do esforço computacional.

\subsection{Abordagem baseada na TW}

O método da Análise Quantitativa do Limiar (AQL) utilizando a TW se baseia na capacidade da AMR em extrair características diferenciadas entre os fenômenos relacionados à QEE. Tal diferenciação é caracterizada pela forma como, usualmente, os detalhes obtidos pela AMR comportam-se na análise de um dado distúrbio.

Afirma-se que com uma janela de dados móvel, a ferramenta poderá, com um alto índice de precisão (100\% de acerto), detectar uma descontinuidade nos sinais, contendo a janela de dados 64 amostras de pré e 64 amostras de pós-fenômeno, ou seja, com meio ciclo de pré e meio ciclo de pós-fenômeno em análise (Oleskovicz et al., 2003).

Desta maneira, a idéia é monitorar constantemente as três fases de tensões e, tão logo sejam caracterizadas descontinuidades nos sinais, ativar, de forma independente, um Módulo Completo (MC) que irá permitir o armazenamento de até 10 ciclos pós-fenômeno, para a completa análise dos sinais pela TW. Este MC é totalmente baseado na AMR e Análise Quantitativa do Limiar (AQL) nos diferentes níveis de decomposição dos sinais em questão.

A Figura 8 apresenta a primeira decomposição da AMR (db4) para um sinal em regime permanente, seguido dos distúrbios de afundamento de tensão, elevação de tensão, ruído, transitório oscilatório, bem como a decomposição de um sinal com interrupção no fornecimento de energia. Pode ser observado que o comportamento do primeiro detalhe de decomposição nitidamente diferencia os fenômenos, exceto para os distúrbios de afundamento e elevação de tensão, o mesmo ocorrendo para a interrupção apresentada. Em função das diferenças, a AQL é explorada para a classificação dos fenômenos no primeiro detalhe de decomposição, com respeito aos distúrbios ocasionados pelo ruído e chaveamento de capacitores. Já para o caso de diferenciação entre os fenômenos de afundamento, elevação de tensão e interrupção momentânea emprega-se o sétimo detalhe de decomposição, como será posteriormente elucidado.

No algoritmo da AQL implementado, como ilustrado pelo fluxograma na Figura 9, um dado sinal de entrada é apresentado e decomposto pela AMR (Arruda, 2003 e Oleskovicz et al., 2003). Nesta etapa são armazenados os detalhes 1, 2, 3, 4 e 7 , bem como a quinta versão da aproximação do sinal. Inicialmente é calculada a diferença (diff) entre os níveis de energia do sétimo detalhe do sinal de entrada e de um sinal em regime permanente, tomado como referência. Tal detalhe contém informações diretas da componente de freqüência de $60 \mathrm{~Hz}$. Sendo assim, variações neste nível de detalhe indicam a presença de fenômenos de nível de freqüência similar ao nível de freqüência do sinal fundamental, ou seja, afundamentos e elevações de tensão, ou interrupções momentâneas. 

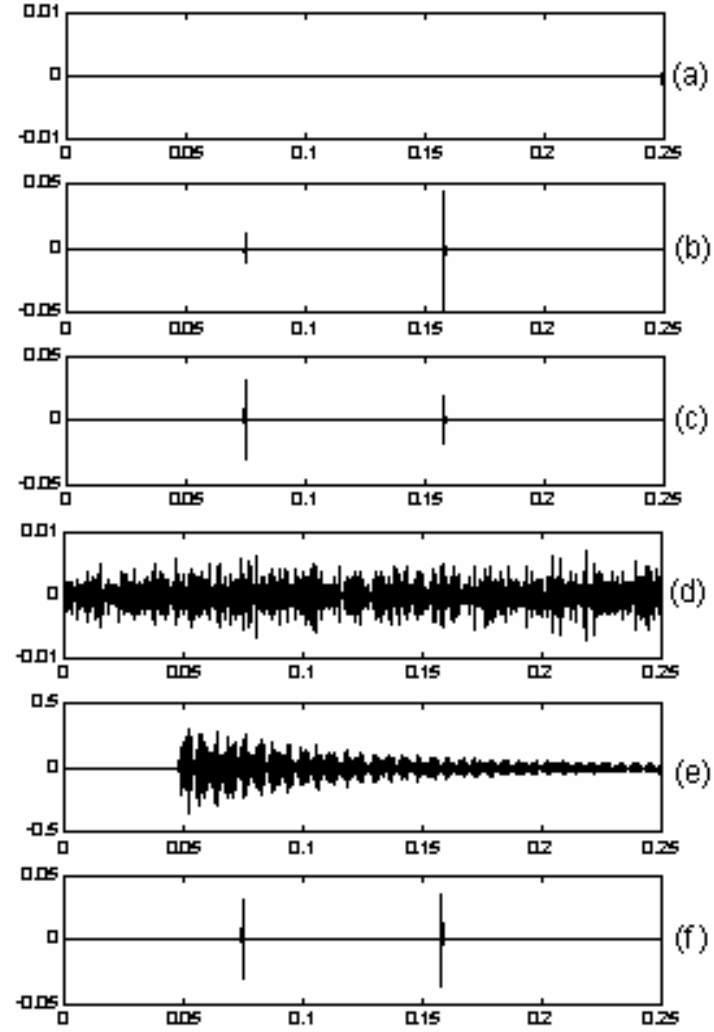

Figura 8: Primeiro detalhe para o regime permanente e os distúrbios em estudo: (a) regime permanente, (b) afundamento e (c) elevação de tensão, (d) ruído, (e) transitório oscilatório e (f) interrupção momentânea.

Uma vez que variações no nível de energia do sétimo detalhe são detectadas, o algoritmo utiliza informações do terceiro nível de detalhe de forma a estimar os instantes de início e fim do distúrbio. Em seguida, a versão da quinta aproximação é usada para estimar a amplitude do distúrbio. Tal versão é utilizada por conter por completo a componente fundamental, tendo sido extraídos os componentes de altas freqüências que poderiam apresentar estimativas errôneas.

Um outro ramo de análise do algoritmo AQL se desenvolve para o caso em que a diferença diff não mostre variações capazes de indicar a presença de distúrbios de afundamento ou de elevação de tensão. Neste caso, o algoritmo AQL utiliza informações do primeiro detalhe para a classificação dos distúrbios de transitórios oscilatórios, ruídos e do sinal em regime permanente. Tal diferenciação é obtida estipulandose limiares que caracterizam os picos apresentados nos detalhes para cada distúrbio, considerando também a forma como os picos aparecem, como por exemplo, a diminuição da amplitude dos picos em se tratando de transitórios oscilatórios. Inicialmente o maior pico de um detalhe do sinal de entrada é comparado a um limiar característico de transitórios osci-

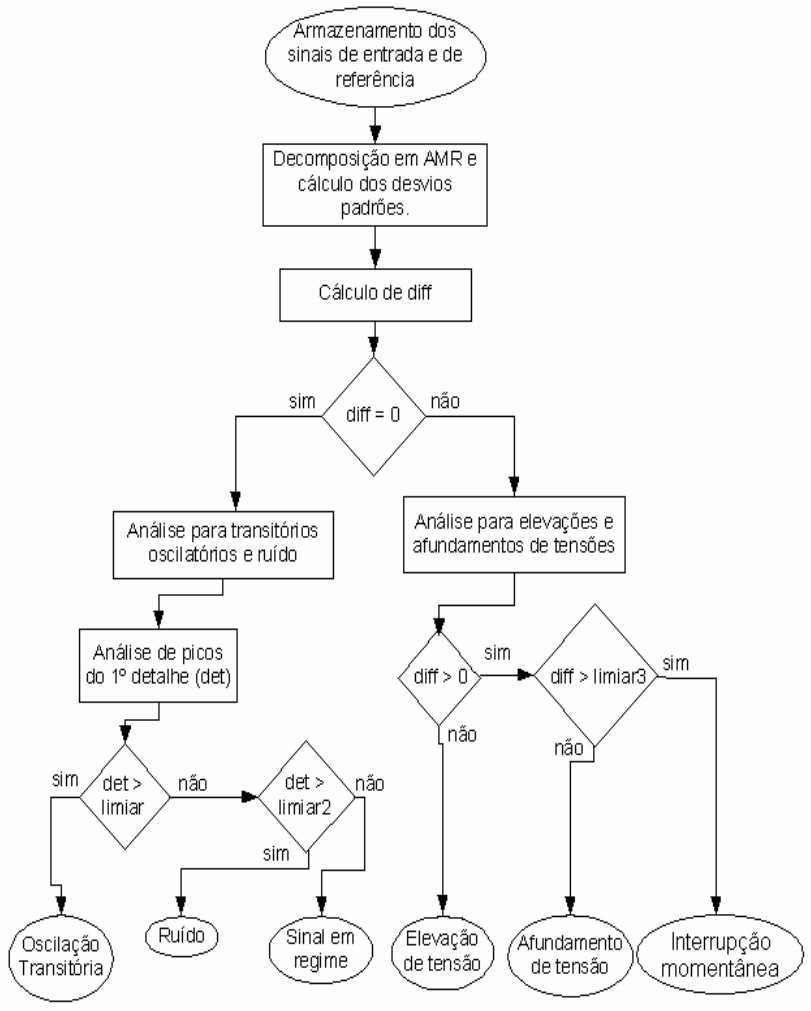

Figura 9: Fluxograma da AQL proposta.

latórios e, para uma resposta positiva, o algoritmo afirma a presença deste distúrbio. Caso contrário tal pico é comparado a picos característicos de ruídos, afirmando ou não a presença destes.

Seguindo a metodologia acima apresentada, efetuou-se de forma automatizada a classificação dos distúrbios pertencentes ao conjunto de teste formado pelas 90 diferentes situações anteriormente mencionadas.

Nos casos analisados, a estimação da duração dos distúrbios de afundamento, elevação de tensão e interrupção momentânea apresentou um nível de acerto expressivo, com erro médio de 5,5\%, para todos os casos testados. Na quarta coluna da Tabela 3, apresenta-se o Erro Médio na Estimação da Duração dos Distúrbios (EMEDD). O erro foi calculado considerando-se a diferença entre o Valor Estimado e o Valor Referencial dividindo-a pelo Valor Referencial.

Ressalta-se também que, considerando todos os casos analisados, o algoritmo apresentou um erro médio de $\pm 4 \%$ na estimação da amplitude dos distúrbios de afundamento e elevação de tensão, juntamente com os casos de interrupção momentânea. 
Tabela 3: Resultados obtidos para classificação do evento com a aplicação da AQL para o conjunto de teste formulado.

\begin{tabular}{|c|c|c|c|}
\hline Fenômeno & $\begin{array}{c}\text { Número } \\
\text { de casos }\end{array}$ & $\begin{array}{c}\text { Classificação } \\
\text { \% (acertos) }\end{array}$ & $\begin{array}{c}\text { EMEDD } \\
\text { \% }\end{array}$ \\
\hline Afundamento & 34 & $91,2 \%$ & \pm 4.2 \\
\hline Elevação & 26 & $100 \%$ & \pm 6.9 \\
\hline Interrupção & 8 & $87,5 \%$ & \pm 4.9 \\
\hline Ruído & 10 & $100 \%$ & - \\
\hline Trans. Osc. & 12 & $100 \%$ & - \\
\hline
\end{tabular}

\subsection{Abordagem baseada em RNAs}

Conforme comentado no item 3, após a detecção de uma descontinuidade ou uma situação anormal sobre o sistema, acusada pela TFJ ou pela TW, um classificador baseado em técnicas inteligentes (RNAs) pode ser ativado para apresentar uma classificação imediata do ocorrido, de maneira alternativa e independente aos demais procedimentos.

Este classificador inteligente é composto por uma RNA independente associada a cada fase de tensão do sinal em análise (Oleskovicz et al., 2003). Cada RNA apresenta 40 unidades na sua camada de entrada, as quais correspondem a 20 amostras de pré e 20 amostras de pós-caracterização do fenômeno, a uma freqüência de amostragem de $2,4 \mathrm{kHz}$. A RNA apresenta somente 5 unidades de processamento na sua camada intermediária e uma camada de saída com 3 unidades (RNA 40 - 5 - 3). Como comentado, o software NeuralWorks foi empregado com o objetivo de se obter as matrizes de pesos fixas que caracterizem as condições de operações sobre o sistema elétrico. Utilizou-se do algoritmo supervisionado "Norm-Cum-Delta Learning Rule", uma variação do algoritmo de retropropagação, o qual é imune às alterações do tamanho da época (número de padrões aleatórios pertencentes ao conjunto de treinamento apresentados à arquitetura a cada iteração). Durante a fase de treinamento, utilizaram-se valores de taxas de aprendizagem distintas para as unidades da camada intermediária e de saída compreendidas entre 0,4 a 0,01 , com valores de momento situados entre 0,2 a 0,01 . As saídas desejadas e esperadas para caracterizar cada fenômeno são observadas na Tabela 4. Esperam-se valores próximos ou iguais a 0 (zero) e 1 (um) para caracterizar as situações.

O conjunto de treinamento foi gerado considerando-se 42 padrões, onde os mesmos caracterizam 8 situações para cada fenômeno de afundamento e elevação de tensão, interrupção momentânea e transitório oscilatório, além de 10 situações de ruídos sobre o sistema. Todos os fenômenos foram caracterizados tomando-se como ângulos de incidência 0 e $90^{\circ}$. Para validar o proposto pelas RNAs, 30 novas e diferentes situações de teste foram geradas e apresentadas à mesma. Do
Tabela 4: Valores esperados pelo classificador inteligente para caracterizar os fenômenos delineados.

\begin{tabular}{|c|c|c|c|}
\hline Fenômeno & Saída 1 & Saída 2 & Saída 3 \\
\hline Afundamento & 0 & 0 & 1 \\
\hline Elevação & 0 & 1 & 0 \\
\hline Interrupção & 0 & 1 & 1 \\
\hline Ruído & 1 & 0 & 0 \\
\hline Osc. Trans. & 1 & 0 & 1 \\
\hline
\end{tabular}

Tabela 5: Resultados obtidos com a aplicação da RNA para o conjunto de teste formulado.

\begin{tabular}{|c|c|c|}
\hline Fenômeno & $\begin{array}{c}\text { Número } \\
\text { de casos }\end{array}$ & $\begin{array}{c}\text { Índice de Acertos } \\
\mathbf{\%}\end{array}$ \\
\hline Afundamento & 8 & $100 \%$ \\
\hline Elevação & 6 & $100 \%$ \\
\hline Interrupção & 4 & $100 \%$ \\
\hline Ruído & 8 & $100 \%$ \\
\hline Osc. Trans. & 4 & $100 \%$ \\
\hline
\end{tabular}

exposto, afirmamos que o módulo inteligente apresentou um índice de $100 \%$ de acerto para todas as situações conforme apresentado na Tabela 5.

\section{CONCLUSÕES}

Neste trabalho, abordou-se o emprego das ferramentas Transformada de Fourier com Janela (TFJ) e da Transformada Wavelet (TW) para detectar, localizar e classificar o distúrbio agregado às formas de ondas de tensão. Além do exposto, os fenômenos delineados também foram classificados, segundo a sua natureza, utilizando-se de um módulo inteligente composto por uma Rede Neural Artificial (RNA).

Em primeira instância, com apenas meio ciclo pósfenômeno, foi possível acusar o distúrbio (TFJ e/ou TW) e classificá-lo dispondo do módulo inteligente (RNA). Cabe salientar que todas as situações de distúrbios evidenciadas sobre o sistema foram corretamente classificadas pelo módulo inteligente (100\% de acerto).

Tendo a confirmação de determinada anomalia sobre o sistema, as abordagens baseadas na TFJ e na TW puderam então analisar o sinal como um todo e relatar os instantes de inserção e extinção, além da classificação do fenômeno sobre o sistema, já apresentado pela RNA.

Dispondo dos resultados observados quando da aplicação da TFJ, contata-se que para a função de detecção do tempo inicial dos distúrbios, o maior erro encontrado está na ordem de 
0,4\%. Já para a classificação do fenômeno, relatou-se um índice de $100 \%$ de acerto para todos os casos analisados. Para a determinação da amplitude envolvida, o maior erro encontrado foi de $1,24 \%$, pelo emprego de uma janela retangular, para as situações de elevação de tensão.

Quando da análise do mesmo conjunto de dados, dispondo agora da TW, tem-se um índice de $100 \%$ para a detecção e de $95,50 \%$ para a classificação dos fenômenos. Para a definição da amplitude de fenômenos caracterizados por afundamentos, elevações e/ou interrupções de tensão, o erro observado está em $4 \%$ do real valor observado. Na mesma idéia, observa-se um erro de 5,50\% com respeito à duração do distúrbio para as mesmas situações.

Basicamente, grande parte dos fenômenos relacionados aos assuntos delineados já foi estudada, mas, por mais amplas que tenham sido estas situações estudadas, novas situações e características específicas ainda devem ser incluídas e trabalhadas no sentido de se alcançar uma implementação prática e confiável ao que foi proposto.

\section{AGRADECIMENTOS}

Os autores gostariam de agradecer ao Departamento de Engenharia Elétrica da Escola de Engenharia de São Carlos USP (Brasil) pelas facilidades proporcionadas quando do desenvolvimento deste trabalho, bem como ao apoio financeiro recebido por parte do $\mathrm{CNPq}$ - Conselho Nacional de Desenvolvimento Científico e Tecnológico, da CAPES - Coordenação de Aperfeiçoamento de Pessoal de Nível Superior e da FAPESP - Fundação de Amparo à Pesquisa do Estado de São Paulo.

\section{REFERÊNCIAS}

Aggarwal, R. and Kim, C.H. (2000). Wavelet transforms in power systems. Power Engineering Journal Apr.:81-87.

Angrissani, L.; Daponte, P.; Apuzzo, M. D. and Testa, A. (1998). A measurement method based on the wavelet transform for power quality analysis, IEEE Transaction on Power Delivery, vol.13, No. 4, Oct.

ALTERNATIVE Transients Program (1987). Rule Book, Leuven EMTP Center (LEC).

Arruda, E. F. (2003). Análise de distúrbios relacionados com a qualidade da energia elétrica utilizando a transformada Wavelet. São Carlos. 121 p. Dissertação (Mestrado) - EESC, Universidade de São Paulo.

Arruda, E. F., Delmont, O. F., Coury, D. V. e Carneiro, A. A. F. M. (2002). Um Estudo das Famílias Wavelets Apli- cadas à Qualidade da Energia Elétrica. Congresso Brasileiro de Automática - CBA2002, 6p, Natal/RN.

Delmont Filho, O. (2003). Utilização da transformada wavelet para caracterização de distúrbios na qualidade da energia elétrica. São Carlos. 92 p. Dissertação (Mestrado) - EESC, Universidade de São Paulo.

Delmont Filho, O., Arruda, E. F., Oleskovicz, M., Coury, D. V. e Carneiro, A. A. F. M. (2004). Técnicas de Localização e Classificação de Distúrbios Relacionados à Qualidade da Energia Utilizando Transformadas Wavelet. XV Congresso Brasileiro de Automática ( XV CBA), Gramado-RS.

Dugan, R. C., McGranaghan, M. F. and Wayne Beaty, H. (1996). Electrical Power Systems Quality, MCGRAWHILL

Gaing, Zwe-Lee (2004). Wavelet-based neural network for power disturbance recognition and classification. IEEE Transactions on Power Delivery, Vol. 19, No. 4, Oct.

Gu Y.H. and Bollen, M.H.J. (2000). Time-frequency and time-scale domain analysis of voltage disturbances. IEEE Transactions on Power Delivery, Volume: 15, Issue: 4 , Oct.

Hensley, G. et al. (1999). Applications of the windowed FFT to electric power quality assessment. IEEE Transactions on Power Delivery, Volume: 14, Issue: 4, Oct. [16]

Huang, S. J.; Hsieh, C. T. and Huang, C. L. (1998). Application of wavelet to classify power system disturbances, Electric Power Systems Research, No. 47, pp. 87-93.

Gaouda, A. M.; Salama, M. M. A.; Sultan, M. R. and Chikhani, A.Y. (1999). Power quality detection and classification using wavelet-multiresolution signal decomposition. IEEE Transaction on Power Delivery, vol. 14, No. 4, Oct.

MatLab ${ }^{\circledR}$, Wavelet Toolbox, 1996-1997, The MathWorks, Inc.

Michelin, C. (1998). Transformada de Fourier e Transformada de Fourier Rápida. Ribeirão Preto. 125 p. Dissertação (Mestrado) - Faculdade de Medicina de Ribeirão Preto, Universidade de São Paulo.

NeuralWorks Professional II/Plus (1998), Aspen Technology Inc.

Oleskovicz, M.; Arruda, E. F.; Delmont Filho, O.; Coury, D. V. e Carneiro, A. F. M. (2003). "Análise da qualidade da energia utilizando transformadas wavelet combinadas às redes neurais artificiais", XVII Seminário Nacional de Produção e Transmissão de Energia Elétrica - 
SNPTEE, Uberlândia, MG, Brasil, Anais do Congresso (CD).

POISSON, O.; RIOUAL, P. and MEUNIER, M. (1999) New signal processing tools applied to power quality analysis, IEEE Transaction on Power Delivery, vol.14, No. 2, Apr.

Poisson, O.; Rioual, P. and Meunier, M. (2000). Detection and measurement of power quality disturbances using wavelet transform, IEEE Transaction on Power Delivery, vol.15, No. 3, Jul.

Santos, C.J. (2000). Transitórios originados pelo chaveamento de bancos de capacitadores da concessionária em um sistema elétrico de distribuição. São Carlos. 107 p. Dissertação (Mestrado) - EESC, Universidade de São Paulo.

Santoso, S.; Powers, E. J.; Grady, W. M. and Holfmann, P. (1996). Power quality assessment via wavelet transform analysis, IEEE Transaction on Power Delivery, vol. 11, No. 2, Apr.

Santoso, S.; Grady, W. M.; Powers, E. J.; Lamoree, J. and Bhatt, S. C. (2000). Characterization of distribution power quality events with Fourier and wavelet transforms, IEEE Transaction on Power Delivery, vol. 15, No. 1, Jan.

Souza A, S. A. (2004). Utilização da Transformada de Fourier Janelada para Caracterização de Distúrbios na Qualidade da Energia Elétrica. São Carlos. 124 p. Dissertação (Mestrado) - EESC, Universidade de São Paulo.

Zheng, T.; Makram, E. B. and Girgis, A. A. (1999). Power system and harmonic studies using wavelet transform, IEEE Transaction on Power Delivery, vol.14, No. 4, Oct. 